\title{
Algoritma Konversi Data Penjualan Microsoft Access Ke Mysql
}

\author{
Muhammad Amrin Lubis \\ Sistem Informasi, STMIK Indonesia Padang \\ maloebis@gmail.com \\ http://dx.doi.org/10.22202/jei.2014.v1i1.1433
}

\begin{abstract}
ABSTRAK
Zombie distro company is a distributor and retailer of garments based in the city of Padang. Currently the company has 14 business units spread across the city of Padang and Pekanbaru. During this time, the company has used to manage the Sales Application transaction data, DBMS used is Microsoft Access. Role of applications that manage the data of purchase, stock, distribution and sales business unit. Each business unit is also conductinga similar difference does not make a purchase to receive the goods but increase the mutation of goods from the head office. Business units everyday to send transaction data to the central office via email. Sales application to importand combineall the data so that it can be seen: inventory, daily sales, transfers and purchases. circum stancessuch as these continue to run for years so ittends to increase the database size to 40MB. Constraint that arises is diminishing Sales Application performance, the management wants to migratea database from Microsoft Access to MySQL. Data Conversion Algorithm Algorithm (AKD) is used to convert sales data. How it works AKD algorithm: (1) equating way connection because both are using different platforms using $O D B C$, (2) read the table one by one from the old database, (3) change the structure of thet able and write it to a new database recorder record, (4) repeat process 1, 2 and 3 until all thet ables in the old database to the new database migration. Users candirectly use the new database that contains the old sale stransaction data. The new database can be accessed by the new Sales Application.
\end{abstract}

Keywords: algorithm, $O D B C$, conversion, migration

\section{PENDAHULUAN}

$\begin{array}{rrrr}\text { Distro } & \text { Zombie merupakan } & \text { perusahaan } \\ \text { distributor dan } & \text { pengecer }\end{array}$ berkedudukan di kota Padang. Saat ini distro memiliki 15 unit bisnis dengan 1 kantor pusat dan 14 kantor cabang tersebar di kota Padang dan Pekanbaru, Riau. Terdapat 2600 record data item barang yang dikelola dalam perdagangan ini yang kemudian dikelompokkan menjadi 11 kategori, 42 record data merk, dengan 52 supplier yang menjadi pemasok untuk memenuhi kebutuhan barang pada distro ini. Barang yang didistribusikan berupa pakaian, sepatu, tas, dan asesoris. Jadi, aktifitas Distro ini menerima supply barang dari supplier, mengelola dan menyimpannya digudang, menjualnya kepada konsumen, dan mendistribusikannya ke unit-unit bisnis. Unit bisnis kemudian mengencernya ke customer dan toko lain.

Distro, setiap mendistribusikan barang ke kantor-kantor cabang selalu menyertakan Surat Jalan sebagai pengantar barang yang dikirim, menjelaskan rincian barang yang dikirim. Unit bisnis kemudian menambah stok barangnya berdasarkan jumlah barang yang diterima, mengelola, menyimpan dan menjualnya kepada konsumen. Setiap sore hari, setelah aktifitas binis ditutup, unit-unit bisnis tersebut mengirim data transaksinya kekantor pusat melalui email. Admin Distro mengimport data tersebut dan menyatukannya dengan database kantor pusat, dengan demikian tampaklah semua aktifitas bisnis kantor-kantor cabang dan kantor pusat.

Kegiatan perekaman data transaksi, selama tahun 2010 terjadi 718 kali transaksi (terdiri dari 16.020 record item) pengiriman barang dari gudang utama kantor pusat ke kantorkantor cabang. Mengeluarkan 3.314 faktur transaksi penjualan yang berisi 64.776 record item barang yang dijual, merekam 667 record faktur transaksi pembelian dengan 6.130 record data barang yang dibeli dan 259 record data return pembelian. Disamping data tersebut masih ada data master sebanyak: 2.679 item barang dan 2.440 record harga pokok barang. Keuntungan atau laba distro ini diperoleh dari hasil penjualan tepatnya nilai dari selisih harga jual dengan harga pokok perolehan. Semua data diatas telah disimpan 
dalam database yang disebut posdb.mdbyang telah dibangun oleh vendor Sangkil Biz.

Database Distro yang ada, dibangun oleh vendor lama, masih dioperasikan, namun saat ini tidak ada lagi kontak antara Distro dengan vendor. Sizedatabase tersebut yaitu lebih 40 MB.

Saat ini, perusahaan tersebut menggunakan DBMS Micorosft Access untuk menyimpan data kegiatan perdagangan perusahaan, tentu dengan keterbatasan kemampuan menampung data yang ada dan minimnya fitur database yang dimilikinya.

Permasalahan yang timbul yaitu pihak manajemen ingin meminta bantuan pengembang software lain untuk mengalihkan pemakaian database manajemen sistem DBMS dari Micorosft Access ke MySQL tanpa mengetik ulang data yang ada, tidak ingin terjadi kehilangan data transaksi, dan operasional perusahaan tidak terganggu sewaktu terjadi proses pengalihan resources. Tentu dengan harapan hasil konversi data yang akurat. Diinginkan database hasil konversi data posdb.mdb ke DBMS MySQL dapat langsung diakses oleh Aplikasi Inventory yang baru.

Mengacu kepada permasalahan yang timbul diatas maka dapat dirumuskan masalah yang dihadapi yakni bagaimana menciptakan algorithmdata conversion agar pihak manajemen terbantu pada proses pengalihan pemakaian DBMS dari Microsoft Access ke MySQL dengan menggunakan Aplikasi Inventory yang baru?

Batasan masalah yang ditetapkan dalam artikel ini terlihat dalam lingkup sebagai berikut: penelusuran struktur database yang lama, mempelajari linking antar table, pengkategorian table master dan transaksi, mencari dan memakai tool penghubung yang berbeperan sebagai connectoruntuk kedua DBMS Micorosft Access dan MySQL, mempelajari bussines rules yang telah ditetapkan oleh vendor terdahulu, dan menetapkan programming yang dipakai.

\section{KAJIAN LITERATUR DAN PEGEMBANGAN HIPOTESIS}

Algoritma adalah kumpulan langkah sistematis untuk memperoleh hasil yang diinginkan [0]. Sebelum sebuah algoritma dijalankan, biasanya ada suatu kondisi awal (initial state)yang harus dipenuhi. Kemudian, langkah-langkah ini proses hingga mencapai suatu kondisi akhir (final state).

Open Database Connectivity (ODBC) adalah strategi interface Microsoft untuk pengaksesan data dalam lingkungan yang heterogen, baik untuk DMBS relational maupun non-relational. Didasarkan pada spesifikasi Call Level Interface SQL Access Group, ODBC menyediakan keterbukaan, vendor yang netral cara pengaksesan data yang disimpan dalam banyaknya variasi properti database komputer pribadi, minicomputer, dan mainframe (support.microsoft.com).[Error! Reference source not found.]

ODBC merupakan universaltool yang dapat digunakan untuk membangun koneksi keberbagai jenis database management system (DBMS) sepeti MySQL, Microsoft Access, SQL Server, Oracle, Postgre, dll. Tool ini diperlukan karena banyak pengembang software yang menciptakan software sendiri dengan aturan main pengoperasian yang mereka tetapkan. Sering ditemukan adanya perbedaan aturan pengoperasian tool tersebut, sehingga pengembang software aplikasi harus mencari solusinya. Programmer dalam membangun sebuah aplikasi management informastiona system (MIS) seperti: Aplikasi Inventori, Sistem Informasi Penjualan dan Laporan Keuangan, dsb, juga menggunakan programming dan DBMS yang bervariasi. Untuk menangani keadaan seperti ini diperlukan software yang belaku universal. Dipilihnya software yang bervariasi oleh pengembang software aplikasi disebabkan kebutuhan, kehandalan, fitur yang tersedia dan kemudahan untuk mendapatkannya.

Konversi data atau migrasi adalah fase di mana desain yang dikembangkan dalam tahap sebelumnya diuji. Migrasi harus dikembangkan secara menyeluruh. Hal ini karena migrasi dapat dilaksanakan hanya sekali, tidak adacoba kedua. ini adalah mengapa proyek migrasi database memiliki tingkat kegagalan yang tinggi [0]. Idealnya, ambil porsi kecil dari sumber data dan diuji ketika mengembangkan migrasi. Pertama 
sebagian data diambil dan semua rutinitas diperiksa untuk fungsi yang tepat. Jika hasilnya memuaskan, volume data yang ada ditingkatkan. Setelah hasil tes keluar, semua perubahan yang diperlukan dibuat untuk migrasi dan merancang untuk membuatnya sempurna. Ini mungkin diperlukan untuk melaksanakan pengujian beberapa kali. Hasil akhir setelah fase ini memberikan proses migrasi yang handal dan cepat.

ODBC yang ada saat ini menyediakan suatu pengaksesan data secara universal, dengan ODBC pengembang aplikasi diperbolehkan pengaksesan secara bersamaan, concurrently, view, dan modify data dari berbagai database yang berbeda [Error! Reference source not found.]. Tidak ada jalan langsung migrasi database dari Microsoft Acces ke MySQL. Oleh karena itu penting untuk menggunakan alat pihak ketiga yang sama datang dengan mengatur sendiri keuntungan dan tantangan [0].

Manfaat

a) Faster Database Migration. Biasanya, suatu perusahaan dengan volume tinggi data mulai TB mungkin lebih suka menggunakan Tools yang tersedia.

b) Easy to track migration and test results. Dengan menggunakan bantuan GUI dan logs konversi melacak dan menguji data bermigrasi lebih baik.

Tantangan

1) High Cost of the tool. Enterprises dengan signifikan rendah mungkin tidak perlu untuk berinvestasi dalam perangkat migrasi yang mahal.

2) Database Value conversion mismatch. Beberapa kunci Bidang Data mungkin memiliki data type pasca mismatch migrasi. Semua peralatan pihak ketiga tidak mengurus konversi data type data base JDE, yang menyebabkan data corruption [0].

\section{METODE PENELITIAN}

Algorithma selalu menekankan pendekatan penyelesaian masalah dengan memperhatikan urutan langkah-langkah logis penyelesaian masalah programming yang disusun secara sistematis. Gambar 1 metodologi yang digunakan sebagai Algorithma Konversi Data Database Microsoft Access ke MySQL mengillustrasikan kedua database yang berada dalam sebuah komputer server, dengan bantuan ODBC memungkinkan dibangun link ke kedua database, dimana kondisi keduanya menggunakan versi DBMS

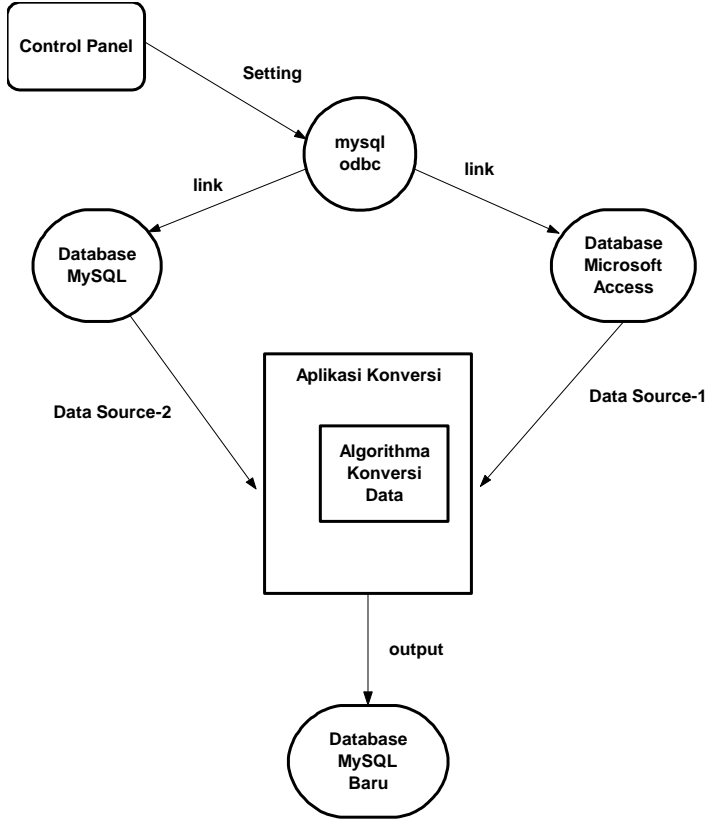

Gambar 1: Algorithma Konversi Data Database Microsoft Access dan MySQL

yang berbeda. Diketahui bahwa kedua DBMS Microsoft Access dan MySQL dibangun oleh dua vendor yang berbeda, untuk itu diperlukan pemakain suatu universal tool untuk membangun koneksi agar keduanya dapat dikenal oleh Algorithma Konversi Data, disinilah peran dari driver mysql odbc. Ada tiga tahapan secara umum yang dilalui agar proses Konversi Data dapat terjadi. Pertama, melalui program Control Panel, yang terdapat di Windows, kedua database tersebut diseting data sourcenya. Hasilnya diperoleh Data Source-1 sebagai alias dari database lama Posdb.mdb, dan Data source-2 sebagai alias dari database baru Distroinventory,pada tahapan ini linking kedua database sudah terjadi. Kedua, melalui masing-masing data source tersebut diatas database dibaca satu persatu. Berdasarkan struktur database lama, satu persatu tabel dibaca, data yang dikandungya dikonversi, kemudian data disalinkan ke tabel baru pada dabase baru 
Distroinventory. Proses perubahan struktur data dan penggantian penggunaan DBMS disebut migrasi. Ulangi perlakuan langkah yang sama untuk semua tabel yang ada pada database lama Posdb.mdb hingga semua data berhasilkan dikonversikan ke database baru Distroinventory. Disinilah peran Algorithma Konversi Data diperlukan yaitu menjembatasi proses migrasi dari database Microsoft Access ke database MySQL, Posdb.mdb ke Distroinventory.

Terakhir, terjemahkan Algorithma Konversi Data menjadi program Aplikasi Konversi Data. Uji algorithma tersebut, ketika program Aplikasi dijalankan, perhatikan langkah demi langka apakah Algorithma Konversi berjalan seperti yang direncanakan? Pastikan data yang menjadi hasil konversi benar dengan cara membandingkan kandungan data tabel yang sama seperti tabel Barang dari kedua database tersebut. Jika benar, maka lakukan proses konversi data untuk semua tabel yang bersumber dari kedua database diatas.

\section{HASIL DAN PEMBAHASAN}

Algorithma Konversi Data (AKD) adalah logika program yang dibangun untuk mengkonversi database dari Microsoft Access ke database MySQL. Konversi data memungkinkan dapat terjadi bila kedua database terkoneksi melalui ODBC disebabkan keduanya memiliki struktur database yang berbeda dan keduanya menggunakan DBMS yang berbeda. Konversi data dilakukan per table untuk 22 table yang ada menggunakan AKD dibawah ini.

Algorithma konversi ini memiliki struktur bangun yang terdiri dari: satu algorithma utama yang memanggil satu method AKD. Method AKD memiliki satu struktur program looping yang berfungsi: membaca record data penjualan secara sequential dari database lama, merubah struktur data dan menulisnya ke dabase baru. Algoritma dimulai dengan: membuat koneksi ke database lama, baca tabel, looping membaca record pada tabel tersebut secara sequential dari awal sampai record terakhir, buat koneksi ke database baru, baca tabel apakah data pada record ini sudah ada dalam tabel baru, jika tidak ada maka rubah struktur record dan salinkan data ke tabel pada database baru, jika tidak maka abaikan tampilkan pesan "Data ini telah ada". Proses konversi ini berlaku untuk masingmasing tabel yang terdapat pada database lama dan kemudian dikoversikan ke database baru.

Dari 22 table yang dibaca menggunakan algorithma AKD maka diperoleh $100 \%$ data berhasil dikonversi dengan waktu kurang dari 5 menit

Sebelum Algorithma AKD dioperasikan pastikan driver mysql odbc telah diinstall terlebih dahulu sebelum proses seting dilakukan. Selain ini pastikan semua struktur table pada Data Source-1 sama dengan struktur table pada Data Source-2.

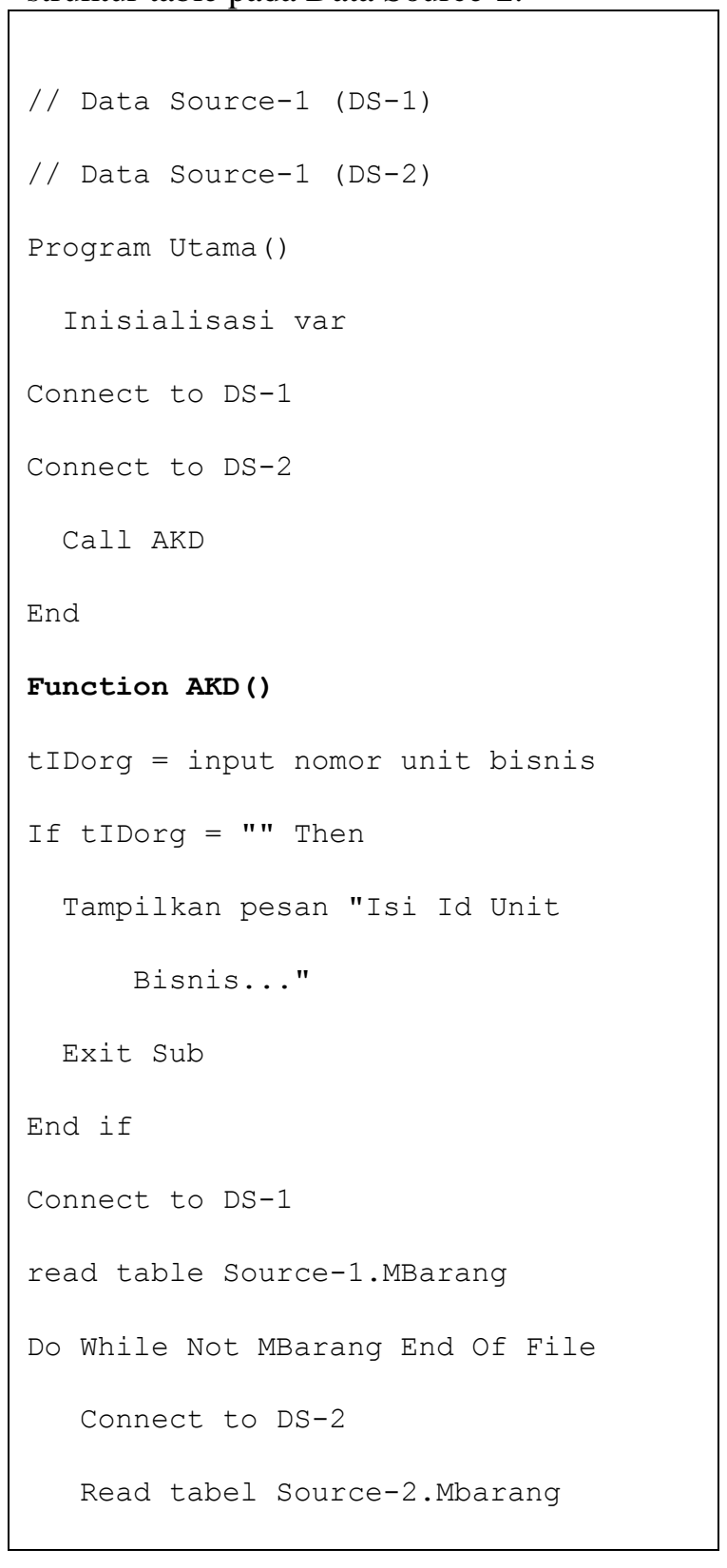


Penelitian Bidang Komputer Sains dan Pendidikan Informatika V1.i1(30-34)

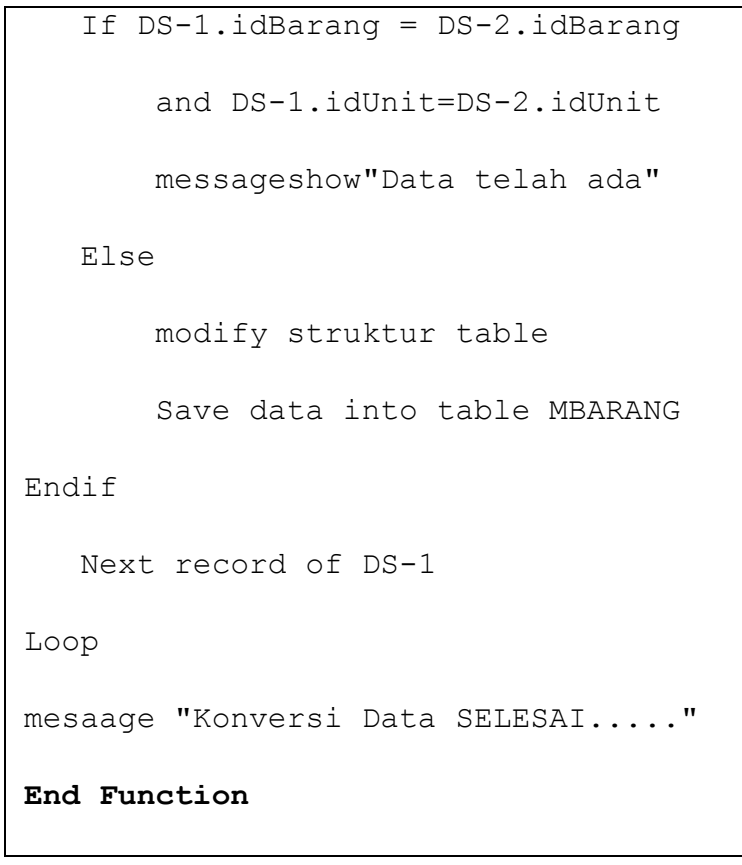

\section{KESIMPULAN}

AKD bekerja dengan cara membaca Data Source-1, record demi record menggunakan metodaaccess sequential, mengikuti bussiness rules yang ada, kemudian menyimpan data setiap record ke Data Source-2. Proses seperti ini dilakukan berulang hingga semua data pada Data Source-1 disalinkan ke Data Source-2. Pada algoritma AKD setiap data yang akan disimpan sebagai record baru ke Data Soruce2, dilakukan pengecekan data terlebih dahulu apakah data yang dimaksud sudah disimpan atau belum, tujuannya untuk menghindari duplikasi data.

\section{PUSTAKA}

Munir,Rinaldi., 2008, Diktat Kuliah IF22153 Matematikan Diskrit Program Studi Teknik Informatika, Istitut Teknologi Bandung.

Microsoft Support web site: http://support.microsoft.com/

Arun Swaminathan, 2012, Database Migration- How hard can it be?, in International Conference on Information Communication and Management (ICICM 2012),IPCSIT vol. 55 (2012) (C) (2012) IACSIT Press, Singapore, DOI: 10.7763/IPCSIT.2012.V55.12.
Ashish Kumar Mandal, 2012, DB2 to Oracle database Migration during JDEdwards Upgrade, Wipro Technologies. All rights reserved 